\title{
Exotic Mo isotope composition in the Nuvvuagittuq Greenstone belt
}

\author{
MATHIEU TOUBOUL ${ }^{1}$, CAROLINE FITOUSSI ${ }^{2}$ AND \\ JONATHAN O'NEIL ${ }^{3}$
}

${ }^{1}$ Laboratoire de Géologie de Lyon

${ }^{2}$ Laboratoire de Géologie de Lyon Terre Planètes Environnement

${ }^{3}$ University of Ottawa

Presenting Author: mathieu.touboul@ens-lyon.fr

The isotopes of Mo, a moderately siderophile element (MSE), can potentially be used as a new tracer of mantle heterogeneities produced as a result of late accretion, i.e. the $\sim 0.5 \%$ addition of extraterrestrial materials to the Earth's mantle after core formation, which is most commonly invoked for explaining the high concents of highly siderophile elements (HSE) and their chondritic relative abundances in the present-day mantle [1]. The rationale for such an approach is based upon (1) the observation that most extraterrestrial materials have different Mo isotope compositions compared with the present-day accessible Earth's mantle. Therefore, late accretion is expected to have changed the Mo isotope composition of the Earth's mantle. (2) the evidence for the preservation of early mantle heterogeneities, in particular in archean rocks, such as those from the Nuvvuagittuq Greenstone Belt (NGB) (Canada, $\geq 3.8 \mathrm{Ga}$ ) [2,3].

Replicated high-precision Mo isotope data for 6 NGB samples obtained with our new N-TIMS method [4] reveal the first massindependant Mo isotopic anomalies ever reported in terrestrial rocks. One sample ( $\mathrm{n}=5$ replicates) shows 'normal' Mo isotope composition, but also exhibits exceptionally high HSE and Mo contents, which suggests contamination via post-eruption processes or during sample collection and processing. The other five samples show resolvable ${ }^{94} \mathrm{Mo}$ and ${ }^{100} \mathrm{Mo}$ deficits, averaging at $-5.0 \pm 1.9 \mathrm{ppm},-4.7 \pm 3.2 \mathrm{ppm}( \pm 2 \mathrm{SE}, \mathrm{n}=18)$, respectively, but no evidence for ${ }^{95} \mathrm{Mo}$ and ${ }^{97} \mathrm{Mo}$ anomalies $\left(\mu{ }^{95} \mathrm{Mo}=0.0 \pm\right.$ $\left.1.5, \mu \mu^{97} \mathrm{Mo}=0.5 \pm 1.4\right)$. The ${ }^{94} \mathrm{Mo}$ and ${ }^{100} \mathrm{Mo}$ excesses observed in meteorites are coupled with ${ }^{95} \mathrm{Mo}$ excesses [5]. Therefore, the exotic Mo isotope pattern of the NGB rocks does not fit with the composition expected for the Earth's mantle before late accretion of meteorites, which should also show significant ${ }^{95} \mathrm{Mo}$ deficits in addition to ${ }^{94} \mathrm{Mo}$ and ${ }^{100} \mathrm{Mo}$ deficits.

[1] Walker, Chemie der Erde, 2009; [2] O'Neil et al., Science, 2008. [3] Touboul et al., Chem. Geol., 2014. [4] Yobregat et al., $J A A S$, in revision; [5] Budde et al., Nature Astronomy, 2019. 